9. Woodson, R. D. and Starr, A.: Atrial pacing after mitral valve surgery. Arch. Surg., 97: 984 (1978).

10. Requests for reprints should be addressed to: Dr. Katsuro Igarashi, Department of Pediatrics, Hirosaki University, School of Medicine, Hirosaki University,
Hirosaki, Japan.

11. Received for publication November $25,1982$.

12. Accepted for publication June 23, 1983.

\title{
Increase of Tryptophan and 5-Hydroxyindole Acetic Acid in the Brain of Ornithine Carbamoyltransferase Deficient Sparse-Fur Mice
}

\author{
C. BACHMANN ${ }^{(25)}$ AND J. P. COLOMBO \\ Department of Clinical Chemistry, Inselspital, University of Bern, Bern, Switzerland
}

\begin{abstract}
Summary
Sparse-fur mice, $28 \mathrm{~d}$ of age with the $\mathrm{x}$-chromosomal inherited defect of ornithine carbamoyltransferase, were used to investigate if tryptophan and the serotonin pathway in the brain are affected in this animal model which closely resembles the human inborn error of metabolism. Increased concentrations of tryptophan and 5-hydroxyindole acetic acid were found in forebrain and brainstem. Application of probenecid, which blocks the efflux of 5hydroxyindole acetic acid from the brain, led to an augmented accumulation of this serotonin metabolite in the affected males. We conclude that the increased concentration of tryptophan in brain and the subsequent increased flux through the serotonin pathway are a consequence of hyperammonemia in this inherited defect of urea synthesis. Surprisingly, increased carbamoylphosphate synthetase was found in the liver of the male sparse-fur mice.
\end{abstract}

\section{Abbreviations}

CPS, carbamoylphosphate synthetase HIAA, 5-hydroxyindole acetic acid HT, 5-hydroxytryptamine

NAGS, $\boldsymbol{N}$-acetylglutamate synthetase OCT, ornithine carbamoyltransferase spf, sparse-fur TRP, tryptophan

Sparse-fur (spf) mice have a x-chromosomal inherited defect of OCT (E C 2.3.3.11). In affected males this leads to hyperammonemia $(10,17)$ as in the human variant of OCT deficiency, an inborn error of metabolism which presents with neurologic symptoms $(1,23)$. These are presumably mediated by changes of neurotransmitters in brain. We chose to investigate metabolites of the serotonin pathway in spf mice, because TRP and HIAA were increased in two animal models where hyperammonemia is present. Studies with rats subjected to portacaval shunting have repeatedly led to the conclusion that chronic liver insufficiency (with hyperammonemia) increases the brain concentration of TRP, the precursor of serotonin (HT), and of HIAA, the main metabolite of HT (11). Because of the multiple metabolic changes encountered in portacaval anastomosis, the particular role of hyperammonemia has not been clearly delin- eated in that complex model (11). For this reason we used a simpler set-up and injected rats with urease. We found that the transport of TRP into the brain was enhanced and that the concentrations of TRP and HIAA in forebrain and brainstem were higher than in pair-fed controls (3).

The following investigations were performed to find out if an inherited defect of an urea cycle enzyme leads to comparable changes in the serotonin pathway. We examined if, in the spf mouse model, the affected males (spf/Y) had increased concentrations of TRP, HT, and HIAA in brain as compared with their unaffected littermates $(+/ Y)$. In order to detect if the flux through the serotonin pathway is altered in spf mice, the indole metabolites were determined also after injection of probenecid, an inhibitor of HIAA transport out of the brain.

\section{MATERIALS AND METHODS}

Spf-females (spf/+) from the Oak Ridge National Laboratory (Oak Ridge, TN) were mated with C57BL*BALBc males (Jackson Lab, Bar Harbour, ME). The offspings were used for the experiments. These were carried out on affected males (spf/Y) which are readily recognized by their sparse fur and on unaffected males (controls, $+/ Y$ ) at the age of $28 \mathrm{~d}$. Data on females (both spf $/+$ and $+/+$ ) are also presented. The animals had not yet been weaned. At 8 a.m. the animals were withdrawn from their mother and placed with a nonlactating female mouse in order to obtain metabolite concentrations unbiased by postprandial amino acid alterations. At 10 a.m. physiologic saline or probenecid ( $200 \mathrm{mg} / \mathrm{kg}$ body weight) was injected intraperitoneally. The animals were decapitated at 11 a.m. and the brain was dissected on an ice cold glassplate within $3 \mathrm{~min}$ into forebrain and brainstem by a precollicular cut after removing the cerebellum. The brain parts were immediately weighed and homogenized in perchloric acid $(0.1 \mathrm{~mol} / \mathrm{l} ; 2.0 \mathrm{ml} / 250 \mathrm{mg}$ of brain) containing ascorbic acid $(0.23 \mathrm{mmol} / \mathrm{l})$, EDTA $(3.4 \mathrm{mmol} / \mathrm{l})$, and vanillic acid as internal standard. The deproteinized samples were applied to an Amberlite CG50, type1, column $(3 \times 10 \mathrm{~mm})$ and the indoles eluted with $3.2 \mathrm{ml} \mathrm{HCl}(1 \mathrm{~mol} / \mathrm{l})$ containing $1 \%$ cystein. The eluate was applied to a SepPakC-18 capsule (Waters Ass., Milford, MA). After washing with $2 \mathrm{ml}$ of bidistilled water the indoles were finally obtained by application of $5.0 \mathrm{ml}$ of sodium acetate/citrate buffer $(0.1 \mathrm{mmol} / 1, \mathrm{pH} 4.3)$ containing $85 \%(\mathrm{v} / \mathrm{v})$ methanol. Ten microliters of the dried extract dis- 
solved in perchloric acid (100 $\mu \mathrm{l}, 0.1 \mathrm{~mol} / \mathrm{l})$ was used for high performance liquid chromatography modified from Loullis et al. (12) and Mefford and Barchas (13). The stationary phase was a Bondapack C18, 10- $\mu$, column $(4.6 \times 250 \mathrm{~mm}$, Waters Ass., Milford, MA); the mobile phase was the above mentioned citrate/acetate buffer but with $5 \%$ methanol $(v / v)$. The quantification of TRP, HT, HIAA, and vanillic acid was done by electrochemical detection at a potential of $0.9 \mathrm{~V}$ (Bioanalytical Systems, La Fayette, IN). In this system indoleacetic acid does not interfere with HIAA.

For characterizing the mice biochemically, the liver was weighed and frozen at $-20^{\circ} \mathrm{C}$ until the OCT, the CPS (EC 6.3.4.16), and the NAGS (EC 2.3.11) activity were determined. OCT was assayed at $\mathrm{pH} 7.7$ and $\mathrm{pH} 9.5$ according to Short et al. (21) with final concentrations of carbamoylphosphate at 4.6 $\mathrm{mmol} / \mathrm{l}$ and ornithine at $2.3 \mathrm{mmol} / \mathrm{l}$. For the homogenization of the liver for the CPS determination (5), a buffer described by Pierson and Brien (15) was used. NAGS activity was measured as described elsewhere $(2,7)$.

The statistical distribution of the results was tested with a Chisquare and a Kolmogorov-Smirnov test for fit with a normal or log-normal distribution. Because some data of enzyme activities and of metabolite concentrations were significantly different from Gaussian distributions the Mann-Whitney test was used for group comparisons. For the same reason, not mean but median values and ranges are given. No clustering of low or high values were found, except for the heterogenous group of female animals.

\section{RESULTS}

As shown in Table 1, the visual assessment of spf males as OCT defective fits the enzyme activity in vitro at $\mathrm{pH} \mathrm{7.7.} \mathrm{The}$ hepatic OCT activity of affected males was $10 \%$ of that found in the non-affected male littermates. As expected, OCT activity showed more spread in female animals than in the male controls

Table 1. Liver enzyme activities in affected and unaffected males and in female mice (median value and range per $g$ fresh weight or per $g$ of protein)*

\begin{tabular}{|c|c|c|c|}
\hline & $\begin{array}{c}\text { Male } \\
\text { Controls } \\
(n=27)\end{array}$ & $\begin{array}{l}\text { Male spf } \\
(n=28)\end{array}$ & $\begin{array}{l}\text { Females } \\
(n=29)\end{array}$ \\
\hline \multicolumn{4}{|l|}{ OCT, pH 7.7} \\
\hline$\mu \mathrm{mol} \cdot \min ^{-1} \cdot \mathrm{g}^{-1}$ & $\begin{array}{c}163 \\
133-278\end{array}$ & $\begin{array}{c}17.7 \S \\
11.4-25.2\end{array}$ & $\begin{array}{c}151 \dagger \\
78-292\end{array}$ \\
\hline$\mu \mathrm{mol} \cdot \min ^{-1} \cdot \mathrm{g} \mathrm{pr}^{-1}$ & $\begin{array}{c}823 \\
608-2143\end{array}$ & $\begin{array}{c}83 \S \\
55-162\end{array}$ & $\begin{array}{c}700 \\
347-1935\end{array}$ \\
\hline \multicolumn{4}{|l|}{ OCT, pH 9.5} \\
\hline$\mu \mathrm{mol} \cdot \min ^{-1} \cdot \mathrm{g}^{-1}$ & $\begin{array}{c}172 \\
151-203\end{array}$ & $\begin{array}{c}175 \\
123-223\end{array}$ & $\begin{array}{c}178 \\
140-250\end{array}$ \\
\hline$\mu \mathrm{mol} \cdot \min ^{-1} \cdot \mathrm{g} \mathrm{pr}^{-1}$ & $\begin{array}{c}858 \\
638-1567\end{array}$ & $\begin{array}{c}872 \\
578-1243\end{array}$ & $\begin{array}{c}882 \\
587-1658\end{array}$ \\
\hline Ratio of activity at $\mathrm{pH}$ & 0.93 & $0.10 \S$ & $0.85 \ddagger$ \\
\hline 7.7/pH 9.5 & $0.85-1.37$ & $0.08-0.16$ & $0.42-1.31$ \\
\hline \multicolumn{4}{|l|}{ CPS } \\
\hline$\mu \mathrm{mol} \cdot \min ^{-1} \cdot \mathrm{g}^{-1}$ & $\begin{array}{c}10.3 \\
6.8-12.0\end{array}$ & $\begin{array}{c}13.2 \S \\
8.6-15.8\end{array}$ & $\begin{array}{c}9.2 \\
4.8-14.2\end{array}$ \\
\hline$\mu \mathrm{mol} \cdot \min ^{-1} \cdot \mathrm{g} \mathrm{pr}^{-1}$ & $\begin{array}{c}47 \\
28-82\end{array}$ & $\begin{array}{r}62 \S \\
37-93\end{array}$ & $\begin{array}{c}51 \\
24-78\end{array}$ \\
\hline \multicolumn{4}{|l|}{ NAGS } \\
\hline $\mathrm{nmol} \cdot \min ^{-1} \cdot \mathrm{g}^{-1}$ & $\begin{array}{c}10.3 \\
2.5-15.8\end{array}$ & $\begin{array}{c}7.4 \\
3.1-15.2\end{array}$ & $\begin{array}{c}9.4 \\
2.2-16.5\end{array}$ \\
\hline $\mathrm{nmol} \cdot \min ^{-1} \cdot \mathrm{g} \mathrm{pr}^{-1}$ & $\begin{array}{c}44 \\
12.5-80\end{array}$ & $\begin{array}{c}33 \\
14-69\end{array}$ & $\begin{array}{c}40 \\
7.2-86\end{array}$ \\
\hline
\end{tabular}

*Abbreviations: OCT, ornithinecarbamoyl transferase; CPS, carbamoylphosphate synthetase; and NAGS, N-acetylglutamate synthetase.

Mann-Whitney test when compared with controls: $\dagger P<0.05, \ddagger P<$ $0.01, \S P<0.001$. and the values were lower. When OCT activity was measured at $\mathrm{pH} 9.5$ there was, however, no difference between the groups. The ratio of OCT activity at $\mathrm{pH} 7.7$ to that at $\mathrm{pH} 9.5$ proved to be the best discriminant. CPS activity in liver was higher in affected males than in controls whereas NAGS activity did not differ.

The TRP concentration in forebrain and brainstem was almost doubled in affected males as compared with the unaffected controls (Table 2). HT was increased only in brainstem whereas HIAA was higher in both forebrain and brainstem of spf males compared with the respective concentrations in control animals. Probenecid application effected a significant accumulation of HIAA in all groups. The HIAA concentration found in spf males after probenecid was higher than in the controls. The molar ratio

Table 2. TRP, HT, and HIAA in forebrain and brainstem (nmol/g) without and after probenecid (median and range)*

\begin{tabular}{ccc}
\hline $\begin{array}{c}\text { Male } \\
\text { controls }\end{array}$ & Male spf & Females \\
\hline
\end{tabular}

Forebrain
TRP

without

12.5

$10.2-17.3$

$(n=14)$

after

15.1

$11.2-18.7$

$(n=13)$

$\begin{array}{cc}21.8^{6} & 13.1 \\ 16.0-44.9 & 9.6-20.4 \\ (n=15) & (n=15) \\ 28.7^{6} & 15.5^{8} \\ 17.4-42.1 & 13.2-23.2 \\ (n=13) & (n=14)\end{array}$

HT

without

1.17

0.93-1.5

$(n=14)$

after

$1.35^{7}$

1.0-1.67

$(n=13)$

HIAA

without

1.16

$0.50-1.50$

$(n=14)$

after

$1.87^{10}$

0.89-1.98

$(n=13)$

1.35

1.0-2.1

( $n=15)$

1.23

0.7-2.0

$(n=13)$

1.19

0.73-1.7

$(n=15)$

1.37

1.0-1.85

$(n=14)$

Brainstem

TRP

without

13.6

9.0-23.4

$(n=14)$

$18.7^{8}$

after

13.9-22.4

$(n=13)$

HT

without

2.21

1.5-3.1

$(n=14)$

after

2.39

1.6-2.9

$(n=13)$

$1.54^{6}$

0.80-2.61

$(n=15)$

$2.17^{2.7}$

0.90-2.95

( $n=13)$

1.10

$0.42-1.65$

$(n=15)$

$1.85^{10}$

$0.90-2.57$

( $n=14)$

HIAA

without

2.70

$26.5^{6}$

18.8-51.4

$(n=15)$

$35.1^{6}$

$25.1-59.2$

$(n=13)$

15.5

9.8-22.9

$(n=15)$

$18.8^{7}$

11.6-28.9

( $n=14)$

$2.94^{5}$

2.12

0.9-4.4

$(n=15)$

$2.84^{3}$

2.0-3.6

$(n=13)$

1.2-3.1

$(n=15)$

2.17

1.1-2.7

$(n=14)$

2.70
$0.74-3.89$
$(n=14)$
$3.86^{9}$
$2.40-5.44$
$(n=13)$

$5.55^{6}$

2.36

$1.50-7.53$

( $n=15)$

$6.56^{6.7}$

0.78-3.91

$(n=15)$

$4.21^{10}$

3.10-11.1

1.60-6.30

$(n=13)$

( $n=14)$

*Abbreviations: TRP, tryptophan; HT, serotonin; HIAA, 5-hydroxyindole acetic acid.

Mann-Whitney test when compared with control: ${ }^{2} P<0.05,{ }^{3} P<$ $0.02,{ }^{4} P<0.01 ;{ }^{5} P<0.005,{ }^{6} P<0.001$.

Mann-Whitney test when compared with the corresponding mice without probenecid: ${ }^{7} P<0.05 ;{ }^{8} P<0.02,{ }^{9} P<0.01,{ }^{10} P<0.001$. 
of HIAA/HT was also more elevated in male spf mice than in the nonaffected males both without (median value forebrain; spf, 1.24; controls, $0.89 ; P<0.02$; brainstem: spf, 1.80 ; controls, $1.20 ; P<0.005$ ) and after probenecid application (forebrain: spf, 1.54; controls, $1.30 ; P<0.01$; brainstem: spf, 2.18 ; controls, $1.77 ; P<0.01)$.

\section{DISCUSSION}

The spf mouse with an x-chromosomal mutation of OCT was characterized by DeMars et al. (10) and Qureshi et al. $(16,17)$, who defined the enzyme defect and showed that the spf males are hyperammonemic and have an elevated serum glutamine concentration. Furthermore, Briand et al. (6) presented evidence that the spf mice have an increased amount of enzymatically defective protein crossreacting with anti-OCT antibodies. Because of the report of increased mortality of affected males after the weaning period (10), we performed our experiments with 28 d-old mice still nursing. In separate groups of animals we found ammonia concentrations in plasma ranging from 55-96 $\mu \mathrm{mol} / 1$ in controls and from 145-202 $\mu \mathrm{mol} / 1$ in spf males. The age of 4 wk was chosen because preliminary experiments with C57BL*BALBc mice had indicated that the concentration of HIAA after peaking at 3 wk of age reached the adult level at 4 wk as shown by Daszuta et al. (9) and that then the response to probenecid was similar to that in adult mice (4).

The main finding of our study is increased TRP and HIAA concentrations both in forebrain and brainstem of affected spfmales. We assume that the increase of TRP concentration in brain is due to the increased transport of this serotonin precursor through the blood-brain barrier. We actually found such an augmented transport in rats, which were hyperammonemic after urease injections, by measuring the uptake of TRP after a single passage after the intracarotid injection of TRP (3). The increased HIAA/HT ratio in the spf mice after probenecid indicates that the increased TRP concentration in brain leads to an increased flux through the serotonin pathway. The similarity between the results obtained on spf mice and on urease-injected hyperammonemic rats supports the view that the increased TRP concentration in brain and the increased flux through the serotonin pathway are a consequence of hyperammonemia. The absence of elevated HT concentrations in forebrain confirms earlier findings in rats subjected to portacaval shunting $(8)$ and could indicate a lack of storage capacity for HT in forebrain.

It could be argued that the enzymatic defect might lead to a delayed maturation of the brain thus affecting neurotransmitter metabolism. The increased TRP and HIAA concentration would be compatible with this hypothesis. However, the absence of a decreased HT concentration in spf males renders such a mechanism unlikely, because a lower HT would be expected in forebrain if the brain of spf males were only at a stage of 3 wk maturation (9). As shown by Stern et al. (22), protein malnutrition could be also partly responsible for the observed changes, but it would not lead to such an increase of HIAA in brainstem. We cannot totally rule out nutritional effects because, due to the technical difficulty of assessing milk intake during nursing, we did not pair-feed the controls and spf mice. Whatever the respective importance of nutrition and hyperammonemia is, we conclude from our data that the serotonin pathway is involved in the pathogenesis of inborn errors of ammonia detoxication and that TRP and HIAA should be considered as parameters of interest when evaluating results of therapeutic trials in animal experiments. Antiserotoninergic agents might be helpful as adjuvants in patients with urea cycle disorders especially when, at a chronic stage, loss of appetite-which could be due to a serotoninergic mechanism-is going to lead to catabolism.

A surprising finding in this study was the small, but significant increase of CPS activity in the liver of spf males. The lower weight of the spf males (spf, $9.3 \mathrm{~g}$; controls, $15.4 \mathrm{~g} ; P<0.001$ ) also observed by others $(10,16)$, which is presumably due to lower milk intake, led us to expect lower CPS (19) and NAGS activity (20) than that in controls. Against our expectation, CPS (but not NAGS) was increased in the spf males. Considering the data of Briand et al. (6) who interpreted the increased protein crossreacting with anti-OCT antibodies in spf males as a compensatory phenomenon counter-balancing the reduced enzymatic OCT activity in the mutant, it is tempting to speculate that the increased CPS activity in spf males is due to similar or even common mechanism. In our experiments, a significant correlation between CPS and OCT (measured at pH 9.5) found in the spf groups $(r=0.4801 ; n=28 ; P<0.01)$, but not in the controls $(r=0.2949 ; n=27$; n.s.) is compatible with such a hypothesis. The measurement of enzyme activity does not allow us to determine whether the increased activity of CPS is due to increased formation of the cytosolic precursor $(14,18)$, increased transport into the mitochondrium and conversion of the preenzyme or to reduced breakdown of CPS (and OCT).

\section{REFERENCES AND NOTES}

1. Bachmann, C.: Urea cycle. In: W. L. Nyhan (Ed.): Heritable Disorders of Amino Acid Metabolism. p. 361 (Wiley \& Sons, New York, 1974).

2. Bachmann, C., Kraehenbuehl, S., and Colombo, J. P.: Purification and properties of acetyl-CoA:L-glutamate $\mathrm{N}$-acetyltransferase from human liver. Biochem. J., 205: 123 (1982).

3. Bachmann, C. and Colombo, J. P.: Increased tryptophan uptake into the brain in hyperammonemia. Life Sci., 33: 2417 (1983).

4. Bachmann, C. and Herschkowitz, N.: (unpublished observation).

5. Brown, G. W. and Cohen, P. P.: Comparative biochemistry of urea synthesis. J. Biol. Chem., 234: 1769 (1959).

6. Briand, P., Cathelineau, L., Kamoun, P., Gigot, D., and Penninckx, M. Increase of ornithine transcarbamylase protein in sparse-fur mice with ornithine transcarbamylase deficiency. FEBS Lett., 130:65 (1981).

7. Colombo, J. P., Kraehenbuehl, S., Bachmann, C., and Aeberhard, P.: NAcetylglutamate Synthetase: enzyme assay in human liver. J. Clin. Chem. Clin. Biochem., 20:325 (1982).

8. Cummings, M. G., Soeters, P. B., James, J. H., Keane, J. M., and Fischer, J. E.: Regional brain indoleamine metabolism following chronic portacaval anastomosis in the rat. J. Neurochem., 27: 501 (1976).

9. Daszuta, A., Barrit, M. C., and Faudon, M.: Developmental variations of brain serotonin, tryptophan, 5-hydroxyindole acetic acid, and noradrenaline and dopamine content in two inbred strains of mice. Dev. Neurosci., 5: 130 (1982).

10. DeMars, R., LeVan, S. L., Trend, B. L., and Russell, L. B.: Abnormal ornithine carbamoyltransferase in mice having the sparse-fur mutation. Proc. Natl. Acad. Sci., U. S. A., 73: 1693 (1976).

11. Fischer, J. E.: Amino Acids in Hepatic Coma. Dig. Dis. Sci., 27: 97 (1982).

12. Loullis, C. C., Felten, D. L., and Shea, P. A.: HPLC determination of biogenic amines in discrete brain areas in food deprived rats. Pharmacol. Biochem. Behav., 'I1: 89 (1979).

13. Mefford, I. N. and Barchas, J. D.: Determination of tryptophan and metabolites in rat brain and pineal tissue by reversed phase high-performance liquid chromatography with electrochemical detection. J. Chromatogr., I81: 187 (1980).

14. Mori, M., Morita, T., Miura, S., and Tatibana, M.: Uptake and processing of the precursor for rat liver ornithine transcarbamylase by isolated mitochondria. J. Biol. Chem., 256: 8263 (1981).

15. Pierson, D. L. and Brien, J. M.: Human carbamylphosphate synthetase I: stabilization, purification, and partial characterization of the enzyme from human liver. J. Biol. Chem., 255: 7891 (1980).

16. Quershi, I. A., Letarte, J., and Oullet, R.: Ornithine transcarbamylase deficiency in mutant mice I. Studies on the characterization of enzyme defect and suitability as animal model of human disease. Pediatr. Res., 13: 807 (1979).

17. Qureshi, I. A., Letarte, J., and Oullet, R.: Spontaneous animal models of ornithine transcarbamylase deficiency: studies on serum and urinary nitrogenous metabolites. Adv. Exp. Med. Biol., 153: 173 (1982).

18. Raymond, Y. and Shore, G. C.: The precursor for carbamylphosphate synthetase is transported to mitochondria via a cytosolic route. J. Biol. Chem., 254: 9335 (1979).

19. Schimke, R. T.: Adaptive characteristics of urea cycle enzymes in the rat. $\mathbf{J}$. Biol. Chem., 237: 459 (1962).

20. Shigesada, K., Tatibana, M.: N-Acetylglutamate synthetase from rat-liver mitochondria. Eur. J. Biochem., 84: 285 (1978).

21. Short, E. M., Conn, H. O., Snodgrass, P. J., Campbell, A. G. M., and Rosenberg, L. E.: Evidence for $x$-linked dominant inheritance of ornithine transcarbamylase deficiency. N. Engl. J. Med., 288: 7 (1973).

22. Stern, W. C., Miller, M., Forbes, W. B., Morgane, P. J., and Resnick, O. Ontogeny of the levels of biogenic amines in various parts of the brain and in peripheral tissues in normal and protein malnourished rats. Exp. Neurol., 49: 314 (1975).

23. Walser, M.: Urea cycle disorders and other hereditary hyperammonemic 
syndromes. In: J. B. Stanbury, J. B. Wyngaarden, D. S. Fredrickson, J. L. Goldstein, and M. S. Brown (Eds.): The Metabolic Basis of Inherited Disease. p. 402 (McGraw-Hill Book Company, New York, 1983).

24. The authors express their gratitude to L. B. Russel at the Oak Ridge National Laboratory, Oak Ridge, USA, for sending us the spf-mice and thank Miss K. Pallmert, Mrs. E. Schneider, Miss U. Pfister and Miss M. Gradwohl for their skillful technical assistance. The work was supported by grant 3.551-0.79 of the Swiss National Science Foundation.

25. Requests for reprints should be addressed to: Dr. C. Bachmann, CZL, Inselspital, CH-3010 Bern, Switzerland.

26. Received for publication January 11, 1983.

27. Accepted for publication July $13,1983$.

\title{
Mathematical Function for Maternal Age in Down's Syndrome
}

\author{
JOHN S. H. TAY ${ }^{(8)}$ AND WILLIAM C. L. YIP \\ Department of Paediatrics, National University of Singapore, Singapore, Republic of Singapore
}

\begin{abstract}
Summary
The purpose of this study is to fit a mathematic function to the observed risk figures for Down's syndrome at various maternal ages. Data from the New York State and Swedish studies were used. It was found that the estimated risks fitted the exponential relationship very well, with a correlation coefficient of over 0.94 . An even better correlation was found (over 0.97) for each 5-yr period in the New York State study. The exponential relationship was given by: $I=a e^{b x}$, where $1 / I$ is the estimated risk; $x$, the maternal age in years; and $a$ and $b$, the constants. In both studies there was considerable variation in the values of $a$ and $b$ with maternal age as well as an excellent correlation between $\ln$ a and b for the 5-yr periods. This function may be used to test various hypotheses for the effect of maternal age in Down's syndrome.
\end{abstract}

An increased incidence of Down's syndrome among the children of older mothers has been well documented. The relationship between the incidence and maternal age is far from linear. A gradual increase in rates of Down's syndrome with maternal age is observed up to about age 30 or 31 yr (3) and a steeper increase is seen thereafter, reaching a figure of 1 in 12 at $49 \mathrm{yr}$ (2). Various hypotheses have been proposed to explain this maternal age effect: maternal exposure to diagnostic radiographs of the abdomen, virus-induced disturbance of chromosomal segregation, "over-ripeness" of the ovum due to delayed fertilization, increase in the frequency of thyroid autoantibodies, and genetic predisposition to non-disjunction (7). The exact mechanism is unclear.

The purpose of this paper is to present a mathematic function to fit the observed risks of Down's syndrome at various maternal ages. This function could then be used to test the likelihood of the various hypotheses.

\section{CONSTRUCTION OF THE MATHEMATIC FUNCTION}

The results of the New York State study (2) and the Swedish study (3) are used (Table 1). Inspection of the risk figures suggests an exponential relationship:

$$
\mathrm{I}=\mathrm{ae}^{\mathrm{bx}}
$$

where $1 / \mathrm{I}$ is the estimated rate and $\mathrm{x}$ the maternal age (yr), and $a$ and $b$ are constants.
The computer program EXPONENTIAL REGRESSION (1) (4) was used on an Apple II microcomputer. This program finds the coefficients of an equation for an exponential curve. The equation is in the following form: $f(x)=a^{*} e^{b x}$, where $a$ and $b$ are the calculated coefficients. The equation coefficients, coefficient of correlation and standard error of $b$ are calculated. The program also allows for the prediction of values of $y$ for given values of $x$, using the calculated equation coefficients.

The standard error of $b$ is calculated according to Armitage (1): the variance of $b$ is given by

$$
\operatorname{var}(b)=s_{o}^{2} / \Sigma(x-\bar{x})^{2}
$$

where $\mathrm{s}_{\mathrm{o}}^{2}$, the residual mean square $=\frac{\Sigma(\mathrm{y}-\mathrm{Y})^{2}}{\mathrm{~N}-2}$.

The expression $\Sigma(y-Y)^{2}$, the residual sum of squares, is obtained as follows:

$$
\Sigma(y-Y)^{2}=\Sigma(y-\bar{y})^{2}-\frac{\{\Sigma(x-\bar{x})(y-\bar{y})\}^{2}}{\Sigma(x-\bar{x})^{2}}
$$

The $95 \%$ confidence limits for the predicted values $(\mathrm{Y})$ are given by:

$$
Y \pm t_{N-2.0 .05} s_{o} \sqrt{\frac{1}{N}+\frac{\left(x_{o}-\bar{x}\right)^{2}}{\sum(x-\bar{x})^{2}}}
$$

for $\mathrm{N}-2$ degrees of freedom on the $t$ distribution. The variable $x_{0}$ is the value of $x$ (maternal age) at which the predicted risk is to be determined. The width of the confidence interval increases with $\left(\mathrm{x}_{\mathrm{o}}-\overline{\mathrm{x}}\right)$, and is a minimum when $\mathrm{x}_{\mathrm{o}}=\overline{\mathrm{x}}$.

The results of the New York State study fitted the exponential model very well, with a correlation coefficient of 0.9752 over the whole age range (20-49 yr) (Table 2). The standard error of $b$, however, was relatively large $(0.3627)$. When the exponential model was applied to the data in segments of 5-yr periods, it was found that the correlation was even better. More significantly, the standard error of $b$ was much lower (Table 2). The equation coefficients $a$ and $b$ generated in this way were used to predict the risk figures (Table 1). It was found that the predicted values were much closer to the observed values when the equation coefficients ( $a$ and $b$ ) calculated for 5-yr periods were used (as would be expected from the smaller standard errors of $b$ ).

Large fluctuations were found in the values of $a$ and $b$ calcu- 